Doi: 10.5212/Uniletras.V.43.18121.2021

\title{
RELATOS DE EXPERIÊNCIAS ACERCA DO ENSINO E DA APRENDIZAGEM DA ESCRITA EM ESPANHOL NA EDUCAÇÃO A DISTÂNCIA DO RIO GRANDE DO NORTE ${ }^{1}$
}

\author{
EXPERIENCE REPORTS ABOUT TEACHING AND \\ LEARNING WRITING IN SPANISH IN DISTANCE \\ EDUCATION IN RIO GRANDE DO NORTE
}

Tatiana Lourenço de Carvalho*

REsumo: No trabalho em questão, apresentamos, a partir dos relatos de professores
e alunos de espanhol como língua estrangeira (ELE) da modalidade de Educação a
Distância (EaD), no estado do Rio Grande do Norte - RN, reflexões sobre como o
ensino e a aprendizagem da escrita desta língua estavam acontecendo em um curso
de Letras-Espanhol. Para tal fim, aplicamos questionários a alunos e professores de
uma disciplina de língua espanhola de nível intermediário. O trabalho baseou-se
teoricamente em Abarca (2008), Baptista (2013), Carvalho (2009, 2010 e 2018), Eres
Fernández et al. (2012), etc. Observou-se, entre outros aspectos, que, embora o ensino
de espanhol nessa modalidade educacional tenha se expandido muito nos últimos
anos no país, ainda há a necessidade de aprimoramento no uso eficiente dos gêneros
textuais digitais disponibilizados no ambiente virtual de aprendizagem (AVA) para
favorecer o ensino da escrita e a interação professor e alunos.

Palavras-chave: Escrita em Espanhol, Ensino e Aprendizagem de Espanhol como Língua Estrangeira, Educação a Distância.

Aвstract: Based on the reports of teachers and students of Spanish as a foreign language (ELE) of the Distance Education (EaD) modality, in the state of Rio Grande do Norte - RN, we present reflections on how teaching and learning to write this language were taking place in a Spanish Language course. For this purpose, we apply questionnaires to students and teachers of an intermediate level Spanish language

\footnotetext{
${ }^{1} \mathrm{O}$ artigo é um recorte da tese de doutorado defendida pela autora na Universidad de Salamanca - Espanha, em 2018, sob orientação do professor Dr. José Luis Herrero Ingelmo. A investigação em questão foi financiada pela Coordenação de Aperfeiçoamento de Pessoal de Nível Superior (CAPES) - Ciência sem Fronteiras (Doutorado pleno no exterior).

"Professora de Língua Espanhola do Departamento de Letras Estrangeiras e docente permanente do Programa de Pós-Graduação em Letras da Universidade do Estado do Rio Grande do Norte. Doutora pela Universidad de Salamanca no Programa de Doutorado em Español: investigación avanzada en Lengua y Literatura. Mestre em Linguística Aplicada pela Universidade Estadual do Ceará e graduada em Letras: Português-Espanhol pela Universidade Federal do Ceará. E-mail: tatianacarvalho1o@yahoo.com.br.
} 
subject. The work was theoretically based on Abarca (2008), Baptista (2013), Carvalho (2009, 2010 and 2018), Eres Fernández et al. (2012), etc. It was observed, among other aspects, that although the teaching of Spanish in this educational modality has expanded a lot in recent years in the country, there is still a need to improve the efficient use of digital textual genres available in the virtual learning environment (AVA) for favor the teaching of writing and teacher-student interaction.

KEYwords: Writing in Spanish, Teaching and Learning Spanish as a Foreign Language, Distance Education.

\section{CONSIDERAÇÕES INICIAIS}

Dada a presença das Tecnologias Digitais de Informação e Comunicação (TDIC) não só na educação, mas também nas mais diversas relações sociais, as questões referentes à comunicação por meio do computador têm levado diversos pesquisadores a tentarem compreender esse impacto das relativamente novas formas de comunicação, em especial por meio dos gêneros textuais digitais ${ }^{2}$ no ensino de línguas. Isto tem afetado diretamente o ensino da leitura e sobretudo da escrita. Neste sentido, tem aumentado o interesse de estudiosos que se ocupam particularmente com as questões referentes ao ensino e à investigação de língua materna e/ou estrangeira relacionando-as às tecnologias digitais, sobretudo, durante este século, no Brasil (ARAGÃO, 2009, ARAÚJO, 2021, CAIADO, 2007, CARVALHO, 2009, 2010 e 2018, DIEB; AVELINO, 2009, LEAL, 2007, MOTTA-ROTH et al. 2007, SOUZA, 2007).

No que se refere ao ensino do espanhol no Brasil, de modo mais particular, não é novidade que esta é uma língua em expansão e de grande importância mundial. Levando em consideração esse crescimento do interesse em aprender a língua em questão no contexto global, no Brasil a realidade não é diferente. Por isso, há mais de um século, o ensino dessa língua hispânica e suas literaturas está presente, de alguma forma, na grade curricular das escolas brasileiras. No entanto, vale destacar que esse processo não segue um percurso unívoco que promova sua permanência nas instituições de ensino do país em todos os períodos históricos ao longo do último século. O ensino de espanhol tem sido atravessado por movimentos políticos de inclusão e exclusão e, por extensão, de resistência. A exemplo, tem-se a aprovação da Lei 11.161 (BRASIL, 2005), a conhecida "Lei do Espanhol”, seguida de sua revogação a partir da Lei 13.415 (BRASIL, 2017).

Diante destes ataques contemporâneos a uma política linguística democrática, o hispanismo brasileiro tem mostrado a sua força por meio de uma agenda de resistência que busca

${ }^{2}$ Gêneros textuais digitais ou, simplesmente, gêneros digitais são aqueles gêneros emergentes com o advento da tecnologia digital, como e-mails, chats, blogs, e-fóruns, entre outros. Também chamados de cybergenres (SHEPHERD; WATTERS, 1998) ou gêneros da web (CROWSTON; WILLIAMS, 1997), eles poderiam ser definidos como os equivalentes virtuais de alguns tradicionais, que se adaptaram às condições do meio digital e, por sua vez, se aproveitaram das possibilidades técnicas oferecidas pela rede para originar novos gêneros. 
garantir a oferta da língua espanhola na educação (COSTA JUNIOR; CARVALHO, 2020), assim como têm feito diversas gerações de professores para instituir políticas linguísticas para a oferta do ensino de espanhol no país em diferentes momentos históricos, inclusive antes da "Lei do Espanhol". As referências ao ensino da língua em questão no Brasil vêm sendo ampliadas e têm sido contadas em publicações recentes, a exemplo de Carvalho e Costa Junior (2020) e Moreira e Pontes (2021) que, respectivamente, reconstroem parte da realidade do ensino de espanhol no Rio Grande do Norte e no Ceará.

Nesse contexto de reconhecimento da importância de aprender espanhol no Brasil, entendemos que a Educação a Distância $(\mathrm{EaD})^{3}$ ganha uma relevância ainda maior na oferta dessa língua, pois serve tanto como meio de socializar o conhecimento mais rapidamente, como instrumento de integração e interação entre alunos e professores de forma mais democrática ao atingir diferentes públicos, inclusive os que vivem em regiões mais afastadas dos grandes centros urbanos.

Considerando esse contexto tecnológico de ensino, é inevitável não concordar com o que dizia García Aretio (2007) quando enfatizava que a EaD não pode ser tratada sem antes atentarmos para a evolução da própria sociedade na qual essa modalidade de ensino está inserida. Separá-la de seu contexto é simplesmente não compreender as propostas que estão sendo realizadas, nem entender o porquê da coexistência de diferentes formas de compreendê-la e desenvolvê-la. Nesse sentido, surge a motivação para a realização deste trabalho sobre o ensino e a aprendizagem da escrita em espanhol como língua estrangeira (ELE) na modalidade a distância em nível superior em um contexto brasileiro no intuito de fazer justiça no que se refere tanto ao reconhecimento das potencialidades da modalidade em questão, como no tocante à importância da ampliação e fortalecimento do ensino de espanhol no único país da América Latina que tem o português como língua oficial.

\section{ENSINO DE ELE NA EAD: O CASO DA ESCRITA}

Nosso interesse de pesquisa com ênfase no ensino da escrita na EaD se deve ao fato do seu uso predominante em ambientes virtuais de aprendizagem (AVA). Além disso, principalmente no que diz respeito à área de ensino da língua espanhola, ainda não conhecemos estudos sobre o desenvolvimento da escrita nos moldes da educação a distância no contexto de coleta de dados para este estudo. Caso existam, em geral, os trabalhos já publicados, tratam

\footnotetext{
${ }^{3}$ Tradicionalmente, a Educação a Distância (EaD) é entendida como o sistema de ensino no qual os alunos recebem o material de estudo (pessoalmente, por correio, e-mail etc.) para o exercício de suas atividades das aulas sem a necessidade de assistência em sala de aula física. Além disso, no Brasil, esta modalidade de ensino se caracterizou, durante muito tempo, por oferecer cursos a distância, com o uso de novas tecnologias por meio de seus cursos virtuais na internet, em combinação com tutorias presenciais em polos de apoio distribuídos em diferentes cidades do país. Hoje em dia, a realidade é diferente, sobretudo no que se refere a ausência de encontros presenciais comuns na modalidade, em virtude da pandemia do Covid-19 que enfrentamos em nosso país desde março de 2020.
} 
do quanto se escreve na EaD, da importância dessa modalidade para o desenvolvimento da escrita, porém pouco ou quase nada se fala sobre contribuições efetivas para o ensino e a aprendizagem de habilidades escritas em aulas da EaD.

Aspectos relacionados ao ensino do texto no que se refere aos processos superiores $\mathrm{da}$ expressão escrita são tratados, por exemplo, em Baptista (2013) ao propor a realização de um estudo cujo foco era o ensino da escrita em um ambiente virtual de aprendizagem (AVA). Lendo mais a fundo o trabalho em questão, no entanto, vemos que a autora se interessa por reflexões sobre o ensino da escrita no AVA, com atenção especial às questões sobre o letramento e a elaboração das atividades presentes nas aulas virtuais que possam promover a competência escrita na língua-alvo de aprendizagem. Verificamos neste estudo que, embora haja uma preocupação mais específica com o ensino da escrita, no que se refere ao desenvolvimento de materiais para o ensino desta habilidade, não há uma preocupação direta com o desempenho docente ensinando a escrever em uma língua estrangeira.

Por sua vez, Eres Fernández et al. (2012) apresentam um trabalho com o foco na produção escrita por meio de diferentes gêneros textuais, abordando tanto aspectos teóricos como práticos para as aulas de ELE. O trabalho foi desenvolvido com o intuito de auxiliar professores de espanhol oferecendo algumas diretrizes, orientações, explicações, exemplos e dezoito sugestões de atividades que podem colaborar para o desenvolvimento da produção escrita no ensino de ELE, porém todas elas com o foco na sala de aula presencial. Somente duas, a que tratou do gênero e-mail e do blog, fizeram alguma referência à comunicação escrita em contexto digital, porém, mesmo assim, com foco nas aulas presenciais. Cabe, portanto, aos docentes do ensino na modalidade EaD fazerem adaptações dessas propostas para o contexto virtual, se assim desejarem, conforme surja a necessidade de trabalho no contexto a distância.

Essa preocupação com as questões de linguagem e interações desenvolvidas por meio das tecnologias digitais através de gêneros textuais, por sua vez, também vem sendo motivo de nossos estudos há mais de uma década quando nos preocupamos com as ações de professores de espanhol diante dos letramentos na web e a utilização de gêneros textuais digitais em suas aulas conforme Carvalho (2009). Porém, neste caso, o estudo ainda era voltado para situações de ensino presencial. Somente ampliamos nossas investigações para o contexto de trabalho desenvolvido por docentes atuantes na EaD, em 2018, especialmente com foco no ensino de escrita nesta modalidade (CARVALHO, 2018). Tais preocupações nos levaram a realizar o estudo que analisou as propostas de atividades e procedimentos metodológicos praticados no ensino da escrita em ELE na EaD em Carvalho (2020). Este trabalho está diretamente relacionado com o artigo que apresentamos agora, pois diferentemente do nosso primeiro estudo, que ocorreu em sala de aula presencial, o artigo em questão visa refletir acerca do que dizem professores e alunos, principais sujeitos dessa experiência na realidade de ensino e aprendizagem de espanhol na EaD, sobre suas vivências nessa modalidade. 
Vale a pena comentar, ainda, quanto a nosso interesse de estudos referente ao ensino do ato de redigir, que reconhecemos que a comunicação clara das ideias por meio dessa habilidade pode ser um processo lento e muitas vezes desgastante no que se refere ao exercício dessa prática nas aulas de línguas, sobretudo se as propostas didáticas não forem motivadoras. Este problema é agravado ainda mais para quem quer aprender a escrever em uma língua estrangeira, porque o aluno não só tem que saber lidar com a estrutura e forma de uma língua que não é a sua, mas também ter conhecimento de um conjunto de regras de adaptação, coerência, coesão etc. Nesse sentido, acreditamos que:

La lengua escrita no es una habilidad que se puede adquirir de forma espontánea, sino que se vale de otras estrategias que el educador puede brindar a los alumnos con el propósito de que descubran sus propias formas de escritura. Esta situación es una justificante para que profesores, autores o investigadores en segundas lenguas hayan hecho publicaciones de libros y manuales que enseñan a sus estudiantes esta destreza. Sin embargo, este material no está basado en una estrategia metodológica acorde con las necesidades de aprendizaje de cada estudiante (ABARCA, 2008, p. 128).

Observando as considerações da autora, reforça-se a ideia de que muitos dos recursos bibliográficos para o ensino da escrita e, consequentemente, as próprias aulas de forma geral carecem de abordagens teórico-metodológicas que conduzam a situações ou atividades de aprendizagem para os diferentes conteúdos que inspiram os alunos a escrever considerando que as motivações desses estudantes devem ser levadas em consideração, além das funções sociais necessárias para o uso da língua escrita em diferentes contextos sociais.

Tal situação de dificuldade do ato de escrever pode ser vista um pouco mais comprometida se considerarmos sua prática em ambientes virtuais universitários como os da EaD. Nestes contextos, espera-se que o aluno escreva com características específicas da comunicação no ambiente acadêmico, além de ter que considerar as especificidades das interações que acontecem nos AVA. Nesses ambientes, as formas de comunicar-se ocorrem predominantemente por meio da escrita em gêneros específicos do meio digital. Muitas vezes, os alunos não estão familiarizados com a escrita acadêmica ou com a escrita no meio virtual. Nesse sentido, os professores precisam ser capacitados para obter melhores resultados a partir do uso dos recursos digitais na escrita dos alunos do ensino superior.

Diante dessa realidade, vale a pena considerar as estratégias e atividades que apoiam o ensino da escrita nas aulas de ELE no contexto da EaD. Para tanto, estamos de acordo com Nunan (2002, p. 36-37), uma vez que este estudioso estabeleceu uma clara diferenciação entre duas formas de compreensão da escrita no ensino de línguas estrangeiras e apontou dois pontos de vista distintos sobre a natureza da expressão. O foco no produto, que se concentra 
no resultado final do ato de escrever, e o foco no processo, que se preocupa tanto com o meio pelo qual o texto foi criado quanto com o produto final em si.

Certamente é este segundo, com o foco no processo, que nos interessa para as aulas de línguas na EaD com atenção à comunicação, por considerar o processo de aprendizagem mais ou tão importante quanto o resultado final. É, portanto, um modelo extremamente pertinente para compreender o ensino da escrita nas aulas de ELE atuais, especialmente na $\mathrm{EaD}$, uma vez que a produção escrita neste contexto pode se dar diariamente ou sempre que seja possível e necessária a interação online.

Em contextos de ensino na $\mathrm{EaD}$, não é apenas interessante que o aluno erradique os erros gramaticais, com base nas práticas tradicionais de ensino e correção da escrita, mas também que melhore a sua redação e os processos cognitivos que isto implica quando ele escreve rascunhos, desenvolve suas ideias redigindo, as revisa, reelabora esquematicamente o texto, envia e reenvia suas produções escritas aos colegas de classe para trocas de revisão, discute sobre os processos de composição escrita, etc.

Nesse sentido, o professor de línguas da EaD deve reconhecer que o ensino da escrita em nível superior nos AVA é uma condição que pode ajudar o aluno a se emancipar, por meio da interação escrita e, também, promovendo a aprendizagem autônoma através dos debates por meio dos gêneros textuais digitais.

\section{O CURSO DE LETRAS-ESPANHOL NA EAD DO RIO GRANDE DO NORTE}

Com a expansão da EaD no Brasil, nasce a Universidade Aberta do Brasil (UAB) e com ela diversos cursos de graduação como a Licenciatura em Letras Espanhol do Instituto Federal de Educação, Ciência e Tecnologia do Rio Grande do Norte (IFRN), em or de março de 2012, único do estado potiguar a oferecer o curso de Letras-Espanhol na modalidade em questão.. Sendo uma instituição brasileira de ensino superior, médio, técnico-profissional e outras modalidades de ensino, os principais objetivos e especificidades da EaD no IFRN são a interiorização de $^{\text {uma }}$ educação de qualidade, a possibilidade de acesso à formação universitária para quem vive longe de grandes centros urbanos e educativos, a expansão da oferta institucional, a diversificação das modalidades educacionais na atenção aos alunos e promoção da inclusão digital.

Considerando essa breve contextualização da EaD no IFRN, as aulas do curso de Licenciatura em Letras Espanhol na instituição em questão, no momento em que realizamos o estudo e coleta dos dados, estavam organizadas da seguinte forma: a oferta propunha um modelo de ensino que mesclava atividades presenciais e a distância. No curso, eram realizados em média dois encontros presenciais, mais uma oficina sobre um tema específico da língua espanhola em cada disciplina por semestre, atendendo a dificuldades específicas dos alunos.

${ }^{4}$ Interiorização refere-se a levar ensino superior de qualidade às cidades do interior do país. 
Além disso, as atividades realizadas a distância no IFRN incluem, até o corrente ano, 2021, a utilização dos recursos do ambiente virtual de aprendizagem (AVA) que são, entre outros, fóruns, chats, arquivos diversos, questionários. O acesso à plataforma virtual é feito através do Moodle, ${ }^{5}$ no endereço: ead.ifrn.edu.br/moodle.

Optou-se por analisar, neste artigo, as respostas referentes a alunos e professores da disciplina "Língua Espanhola IV" porque se esperava um nível intermediário de ensino e aprendizagem da língua nesse período; portanto, já deviam se comunicar por meio da escrita em espanhol dentro do AVA, habilidade esta imprescindível para a modalidade em questão e de interesse de estudo nesta pesquisa. Além do mais, no programa da disciplina foi possível observar a informação que reforça e justifica a nossa escolha de investigação num contexto em que, entre outras questões, o desenvolvimento da escrita visa: "Compreender e produzir textos complexos sobre vários temas. Desenvolver a competência comunicativa e a compreensão oral e escrita e habilidades de produção" (PACHERREZ VELASCO et al. 2012, p. 98).

Os principais agentes da EaD em geral e do contexto observado são: tecnologias, professores e alunos. Mais especificamente, no caso do IFRN, as tecnologias são basicamente representadas pelas ferramentas disponíveis na plataforma virtual Moodle.

No que diz respeito à função docente, como existem várias na modalidade a distância, vale a pena especificar, pelo menos, aquelas que nos interessam na análise deste artigo, que são o professor formador, o professor tutor e o professor conteudista.

O professor formador é responsável, entre outras atividades, pela gestão dos conteúdos programados, orientando os alunos nas atividades didático-pedagógicas e preparando, quando necessário, o material didático para atender às necessidades emergentes ao longo do curso.

No que se refere à ação do professor tutor a distância, este atua dando suporte ao professor formador e ao professor tutor presencial na interação direta com os alunos e está à disposição para esclarecer dúvidas destes, pedagógicas ou não.

O professor conteudista, como o próprio nome já expressa, é responsável por preparar o material didático impresso ou em outros formatos.

Por fim, os alunos assumem um papel especial na $\mathrm{EaD}$, por serem os principais responsáveis de seu processo de aprendizagem nesta modalidade. Sem disciplina, organização e caráter autodidata, o discente da modalidade em questão não consegue cumprir sua função de aprendizagem.

Considerando a descrição das especialidades dos agentes do curso em EaD observado para análise neste artigo, passamos agora aos dados coletados por meio dos questionários.

\footnotetext{
${ }^{5}$ Moodle é uma licença gratuita para suporte de software de aprendizagem. É um dos AVA mais usados em todo o mundo porque é um sistema aberto. É desenvolvido de forma colaborativa por uma comunidade virtual, que reúne programadores e desenvolvedores de software livre, administradores de sistema, professores, designers e usuários de todo o mundo.
} 


\section{Dados REFERENTES AOS QUESTIONÁRIOS APLICADOS}

Aplicamos um questionário a cada um dos participantes da disciplina observada (um professor formador, um professor tutor, um professor conteudista e dez alunos da turma) durante o processo de ensino e aprendizagem de espanhol na EaD do curso de Licenciatura em Letras Espanholas do IFRN, mais especificamente, da disciplina de Língua Espanhola IV.

Por razões éticas em pesquisas envolvendo seres humanos, não identificaremos o ano da coleta de dados nem quem são esses participantes. Por isso, trataremos os docentes investigados simplesmente como professor formador, professor tutor e professor conteudista; os alunos, identificaremos cada um como Aluno 1 (Al.1), Aluno 2 (Al.2), Aluno 3 (Al.3) e assim por diante, até o Aluno 10 (Al.10). Como os participantes são professores de uma mesma disciplina, temos a contribuição de todos que fizeram parte do processo de trabalho dentro de um mesmo componente curricular em suas respectivas funções, além dos dez alunos que aceitaram participar do estudo.

O objetivo da aplicação dos questionários foi verificar qual o tratamento dado à habilidade escrita tanto pelos professores quanto pelos alunos nas experiências em EaD em questão. As perguntas foram de respostas abertas, embora algumas oferecessem a possibilidade de respostas de múltipla escolha, antes da possibilidade de desenvolvê-las de forma dissertativa. O questionário foi planejado dessa forma para dar oportunidade aos alunos e professores de expressarem suas opiniões e de descreverem situações ilustrativas de suas respostas, se fosse o caso.

A seguir, apresentamos os dados divididos em duas partes, respostas dos professores e respostas dos alunos, referentes ao que os participantes comentaram nos questionários.

\section{RESPOSTAS DOS PROFESSORES NOS QUESTIONÁRIOS}

Esta sessão é dividida em quatro subseções referentes às quatro questões dos questionários dirigidos aos professores sobre como desenvolveram as suas atividades no contexto da análise deste estudo com o foco na escrita em espanhol.

\section{ForMAÇÃO PARA O ENSINO DA ESCRITA NA EAD}

Quando perguntamos se os professores haviam realizado algum treinamento para o ensino da escrita por meio dos recursos digitais disponíveis no AVA utilizados no curso da EaD em questão, nenhum deles declarou ter feito curso nesse sentido. Tampouco declararam terem lido alguma bibliografia que os auxiliassem em seus trabalhos como docentes na modalidade a distância. Além disso, não temos conhecimento, até hoje, que haja a possibilidade de treinamento específico referente ao ensino das quatro habilidades de comunicação no ensino 
de espanhol no contexto da coleta de dados para o nosso estudo oferecendo a base necessária no uso dos recursos disponíveis no AVA. Entendemos que isso ainda seja uma realidade, entre outros motivos, devido à relativa novidade que esta modalidade de ensino, especificamente da língua espanhola na EaD, representa para o contexto educacional brasileiro, sobretudo no Nordeste, onde atuamos e conhecemos mais de perto essa realidade.

No entanto, os dois professores que já haviam trabalhado na preparação do material para o curso se manifestaram: o professor formador, que contemplava as quatro habilidades comunicativas da mesma forma na preparação do material, mas sem especificar necessariamente como em sua resposta; enquanto o professor conteudista não especificou como trabalhava a escrita ou qualquer uma das outras habilidades na elaboração dos materiais, mas declarou que o manual didático utilizado naquele curso permitia ao aluno desenvolver habilidades diversas e que cabia, de acordo com palavras desse docente, ao professor acompanhar o desempenho dos alunos no processo de aprendizagem.

Levando em consideração como os professores se manifestaram sobre a elaboração do material, e que nenhum expressou especificamente a preocupação com o uso de tecnologias no planejamento de atividades adequadas à EaD, observamos que é necessária uma formação docente específica para o trabalho nessa modalidade, não só para aprender sobre o uso de ferramentas digitais, mas, sobretudo, aprender a utilizar de forma adequada os recursos do AVA no ensino que não seja uma mera reprodução do que acontece em aulas tradicionais de línguas (CARVALHO, 2018). Tal mudança de postura docente deve levar em consideração que o contexto é diferente: muito mais tecnológico, podendo ser, também, muito mais interativo, conforme se direcione nas atividades dos materiais e aconteça a condução da aula.

\section{PROMOÇÃO DA INTERAÇÃO ESCRITA EM ESPANHOL COM OS ALUNOS}

Ao responder à questão sobre como se promoveu a interação escrita em espanhol com os alunos, todos os professores afirmaram já terem desenvolvido atividades essencialmente docentes no âmbito da EaD. O professor formador declarou que interagia com os alunos "frequentemente", enquanto os demais, o professor tutor e o professor conteudista, relataram "sempre" interagir com os alunos. Todos comentaram sobre a grande importância da gestão da escrita na EaD; no entanto, também revelaram que havia dificuldades em trabalhar com essa habilidade no contexto em questão.

Dentre os problemas enfrentados, o professor formador afirmou que nem todos os alunos têm motivação para aprender por meio da EaD e alguns até interagem com pouca frequência no AVA e que, quando isso acontecia, procurava estimulá-los para que houvesse uma mudança de postura rumo a uma maior interação, mesmo sabendo que alguns estudantes buscavam aprender em seu próprio ritmo, sem interagir. 
Vale ressaltar que a interação, na EaD, é um dos indicadores de que o aluno está "presente" nas aulas, porém, se levarmos em consideração o caráter autodidata que se espera na modalidade, é importante que o discente consiga demonstrar bom desempenho de forma autônoma, conciliando suas ações com momentos de interação no contexto acadêmico virtual, uma vez que a competência desenvolvida individualmente nem sempre é o que se espera para medir o grau de habilidade comunicativa em uma língua estrangeira. Tanto a interação entre alunos e professores através das TDIC como a autoaprendizagem que estas promovem se complementam. Cabe, portanto, aos professores, na preparação e planejamento das aulas virtuais, buscar promover um equilíbrio entre esses dois componentes no momento da elaboração e condução das atividades de escrita.

\section{GÊNEROS TEXTUAIS DIGITAIS PRESENTES NO AVA E UTILIZADOS NAS INTERAÇÕES ESCRITAS}

Ao responder à pergunta sobre quais eram os gêneros textuais digitais responsáveis por promover a interação virtual entre professores e alunos no Moodle, os dois professores que responderam a esta pergunta, o formador e o tutor, aqueles que estão em contato mais direto com os discentes, mencionaram o uso do gênero virtual fórum, embora o tutor também tenha destacado o uso de mensagens privadas a depender dos propósitos comunicativos. O fórum é, de fato, o gênero textual mais empregado na maioria das experiências em EaD que temos conhecimento no país sobretudo porque nele se pode observar a construção do conhecimento a partir da interferência de vários alunos com suas problematizações, questões, dúvidas, esclarecimentos, soluções etc. (CARVALHO, 2020). O fórum é, portanto, entendido como um espaço onde há um encontro de pessoas criado com o objetivo de promover o debate sobre um mesmo conteúdo discursivo a respeito de um determinado tema.

Segundo nossa observação, em diversas experiências na EaD, sabemos que a diferença entre o fórum e a mensagem privada é que a primeira é um gênero de comunicação pública e todos os participantes da disciplina têm acesso ao que nele está escrito, enquanto o segundo, como o próprio nome revela, é caracterizado pela comunicação privada. A partir desses dois gêneros virtuais, muitas vezes é possível trabalhar as habilidades escritas, já que são os meios de comunicação virtual mais recorrentes no AVA do contexto observado na coleta de dados desta pesquisa. De forma mais particular, o professor pode corrigir a escrita de cada aluno individualmente através das mensagens privadas e o fórum pode ser aproveitado para o ensino da escrita quando o objetivo é tratar de temas de interesse de todo o grupo.

Outro dos gêneros virtuais comuns e bastante utilizados no AVA em questão e que não foi citado por nenhum dos professores que participaram do questionário é o chat. Esse meio de comunicação virtual possibilita uma interação escrita síncrona, diferente dos demais, ou seja, professores e alunos precisam estar conectados ao mesmo tempo para que o "diálogo" ocorra. O fato de o chat não ter sido mencionado pelos professores pode ter ocorrido devido a algumas dificuldades de conexão, o que não é incomum em algumas regiões menos favorecidas 
economicamente no contexto específico da UAB. Além disso, outro agravante para o uso desse gênero no contexto observado, é que muitos alunos realizavam atividades laborais durante o horário comercial e os próprios professores também exerciam outras funções docentes em contextos presenciais durante a semana. Esse fato tornou a compatibilidade de tempo ainda mais difícil para a comunicação síncrona no AVA.

\section{TRATAMENTO DADO À ESCRITA NO ENSINO E NA PREPARAÇÃO DO MATERIAL EAD}

Quando questionados sobre o tratamento que deram à escrita durante o ensino e a preparação do material da EaD, além das tarefas específicas criadas para a realização de atividades de produção escrita pelos alunos, os professores de espanhol da EaD em questão destacaram que, ao ensinar tal habilidade, os recursos disponíveis no AVA estimulavam e favoreciam a constante produção escrita dos alunos. Exemplo disso foi a comunicação que eles afirmaram que se dava por meio dos fóruns que, segundo o professor formador, eram o meio pelo qual aconteciam os debates e era por meio deste gênero que se instigava o desenvolvimento da escrita dos alunos.

No que se refere à ação docente, com vistas ao ensino da escrita na EaD, observamos na exposição do professor formador certa maturidade e sentido crítico na utilização dos recursos digitais da plataforma virtual, uma vez que este assumiu criar e promover um contexto favorável à aprendizagem da língua espanhola. Já o professor tutor, quando se referiu à sua atuação para favorecer o desenvolvimento da competência escrita dos alunos, não destacou o uso das ferramentas específicas do meio digital. Talvez isso tenha ocorrido porque o docente em questão, durante o período de coleta de dados, levava pouco tempo trabalhando na EaD e/ou porque tinha a concepção de que é primeiro o professor formador que deve criar as atividades no contexto em questão. No entanto, o tutor também pode, em colaboração com o formador, propor a elaboração de atividades, embora a sua principal tarefa seja acompanhar mais diretamente a aprendizagem dos alunos, levantando questões e incentivando a sua participação.

Ao responder à pergunta sobre qual é o tratamento dado à habilidade escrita na elaboração do material da EaD, o professor conteudista, por sua vez, enfatizou, mais especificamente, que trabalhava questões relacionadas à cultura como forma de estimular a motivação dos alunos para escreverem sem, no entanto, destacar como isso acontecia, se era recomendada ou não a utilização dos recursos virtuais disponíveis no AVA. Ou seja, as propostas de redação, conforme sua resposta no questionário, foram tratadas sem levar em consideração os recursos tecnológicos no momento de sua elaboração ou o professor em questão simplesmente não mencionou como ocorreu essa incorporação da tecnologia. 


\section{RESPOSTAS DOS ALUNOS NOS QUESTIONÁRIOS}

Assim como na seção anterior, esta subdivide-se em subseções referentes às perguntas do questionário dirigido aos alunos sobre como desenvolveram suas atividades discentes no contexto da educação a distância. Neste caso, as especialmente relacionadas à aprendizagem da escrita na língua espanhola foram três, questões estas das quais trataremos a seguir.

\section{IMPORTÂNCIA DO ENSINO DA ESCRITA NA EAD}

Ao responder à pergunta sobre a importância do ensino da escrita na $\mathrm{EaD}$, os alunos deveriam levar em consideração os níveis que já haviam passado e ainda estavam estudando no curso, ou seja, o inicial e o intermediário. Alguns não responderam adequadamente a esta pergunta; portanto, as respostas que não levaram em consideração o assunto tratado não serão discutidas aqui.

Em relação ao contexto do nível inicial, todos os dez alunos, exceto Al.4 e Al.7, responderam adequadamente à questão e avaliaram a importância dada ao ensino da escrita no nível inicial com notas entre 5 (cinco) e 10 (dez). Os dois que deram notas mais baixas, 5 (cinco) e 6 (seis), foram os estudantes Al.1o e Al.9, respectivamente. O primeiro justificou sua pontuação afirmando que no nível inicial não se pode exigir que o aluno escreva tanto como se já tivesse estudado ou tido contato com a língua espanhola em algum período anterior de sua vida. Já Al.9 considerou que um estudante universitário deve possuir um domínio mínimo de escrita antes de iniciar seus estudos na universidade. Para esse aluno, se supõe que o discente deva iniciar uma graduação com habilidades básicas de produção de texto. Essa percepção de Al.9, idealmente, é o que deveria acontecer na prática, no entanto, quando se trata de uma língua estrangeira, na maioria das vezes o estudante brasileiro nem sempre inicia as aulas na universidade com um conhecimento mínimo da língua. Muitos só têm o primeiro contato proficiente com uma língua estrangeira já na universidade, o que dificulta o trabalho da formação de bons professores de línguas, por exemplo.

Os outros alunos que avaliaram a importância do ensino da escrita no nível inicial com notas 8 (oito) (Al.5), 9 (nove) (Al.2) e 10 (dez) (Al.1, Al.3, Al.6 e Al.8) basicamente afirmaram, como justificativa de suas respostas, que a escrita é um dos principais meios de comunicação entre professor e alunos na EaD e, por isso, consideram ser tão importante, desde o nível básico, que os alunos já desenvolvam essa habilidade e se tornem familiarizados com ela.

Ao ler as respostas dos alunos sobre o que eles pensavam sobre a importância do ensino da escrita no nível intermediário, não levamos em consideração as respostas dos alunos Al.2, Al.4 e Al.5, uma vez que eles não avaliaram ou comentaram a questão de acordo com o que foi perguntado. Dos demais alunos que responderam apropriadamente, a nota mais baixa, um 7 (sete), foi dada por Al.9, que utilizou o mesmo argumento dado para a resposta dada com relação ao nível inicial, de que o aluno do ensino superior deveria iniciar o curso já com 
domínio da habilidade escrita mesmo na língua estrangeira. Por sua vez, Al.6 atribuiu um 8 (oito) para o grau de importância do ensino da escrita no nível intermediário; entretanto, não justificou sua resposta. Os demais, aqueles que pontuaram com um 10 (dez), os alunos Al.1, Al.3, Al.7 e Al.8, basicamente reconheceram a importância do ensino da escrita em nível intermediário, levando em consideração o trabalho do profissional docente para o qual eles estão sendo formados, que precisa dessa habilidade na sala de aula cotidianamente.

\section{APRENDIZAGEM DA ESCRITA EM LÍNGUA ESPANHOLA NA EAD}

Ao observarmos como se deu o desenvolvimento da aprendizagem da escrita em ELE na EaD, de acordo com as respostas dos alunos, vimos que os discentes Al.2, Al.3, Al.6, Al.7, Al.8 e Al.1o declararam perceber claramente a evolução a partir do momento em que passaram a ter disciplinas mais específicas do espanhol, em um nível intermediário, o que exigia um uso mais contínuo da língua em questão em relação às disciplinas de nível inicial, nas quais algumas vezes podiam se comunicar em português por ainda estarem em fase introdutória de aprendizagem da língua estrangeira. Apenas dois alunos, Al.1 e Al.4, declararam não haver diferença entre os dois níveis de aprendizagem sem especificar o porquê tiveram essa impressão. Já Al. 9 afirmou que não conseguiu responder à pergunta exatamente devido ao pouco contato que afirmou ter com os professores.

A seguir, citamos a resposta de Al.7 na íntegra, pois ela sintetiza o que seus outros colegas também responderam sobre a mesma questão:

A escrita na EaD é desenvolvida por meio de atividades de avaliação com prazos, bem como por fóruns e questionários pelos quais também somos avaliados. Entre o nível inicial e o intermediário há uma pequena diferença devido ao fato de que no nível inicial escrevemos muito na língua materna, o que facilita a construção dos trabalhos (Al.7, 2015, s.p.).

Vale comentar também, no tocante a essa questão sobre o processo de ensino e aprendizagem da escrita nesta modalidade, que alguns alunos mencionaram a interação escrita por meio de gêneros digitais, principalmente dos fóruns. Porém, há algo que nos chama a atenção sobre a forma como os discentes percebiam as atividades interativas no AVA: há uma certa preocupação com os prazos de conclusão e com a entrega das atividades, como pode ser verificado no comentário de Al.7 citado anteriormente. Isto é bastante intensificado quando se trata da modalidade de ensino a distância por meio da utilização de ferramentas digitais programadas com esse objetivo. Neste sentido, cabe aos professores em contrato didático com os estudantes decidirem sobre datas de provas ou possíveis prorrogações de envios de trabalhos. Isto, claro, sem comprometer o calendário geral da disciplina. 


\section{AutoAVALIAÇÃO DA APRENDIZAGEM DE ESCRITA EM ESPANHOL NA EAD}

Agora, apresentamos os dados referentes à questão de como os alunos se avaliam como escritores do espanhol como língua estrangeira. Todos reconheceram que ainda havia muito espaço para melhorias em suas produções escritas e alguns enfatizaram que a oralidade também precisava ser desenvolvida. As notas que os alunos deram a si próprios foram muito baixas no quesito da produção escrita. Apenas os dois primeiros, Al.1 e Al.2, se deram a nota mínima para a aprovação no curso em questão, um 6 (seis). Deve-se levar em consideração que esses alunos ainda estavam em processo de aprendizagem da língua, ou seja, se ponderamos a nota considerando o nível de aprendizagem em que eles se encontravam no momento da coleta de dados, talvez ela aumente um pouco mais a partir do momento em que os alunos se percebam progredindo nos níveis de ensino e não apenas avaliem os problemas existentes a partir do aumento do grau de dificuldade que é normal do processo evolutivo durante a aprendizagem. Pelo que percebemos em suas respostas, tal progresso, a partir da percepção das dificuldades de aprendizagem e até dos erros cometidos, não foi levado em consideração na autoavaliação dos alunos. A maioria (Al.5, Al.6, Al.1o e Al.9) se pontuou com notas entre 5 (cinco) e 5,5 (cinco vírgula cinco) enquanto aprendizes da escrita em língua espanhola. No entanto, dois outros alunos (Al.4 e Al.8) se deram notas ainda mais baixas, um 3 (três) e um 4 (quatro), respectivamente. Curiosamente, o aluno que deu a nota mais baixa foi quem declarou sentir falta das aulas presenciais.

Levando em consideração esses dados de autoavaliação dos alunos e todos os demais apresentados neste artigo, entendemos que, antes de mais nada, todos os envolvidos na EaD devem acreditar na eficácia dessa modalidade de ensino para que haja avanços nos resultados obtidos nela. Aquele que se matricula em um curso a distância deve saber que terá que aprender fora de uma sala de aula convencional. $\mathrm{Na} \mathrm{EaD}$, o estudante é quem cria seu próprio cronograma de aprendizagem e deve ser capaz de executá-lo de forma eficaz. Sentir "falta" de outro contexto de ensino e aprendizagem diferente do possível de acontecer na modalidade em questão não ajudará a cumprir o seu objetivo nesse processo educativo, que é formar e capacitar pessoas que, por motivos diversos, não podem frequentar salas de aula físicas. Os professores também devem acreditar na modalidade para desenvolver suas habilidades pedagógicas, por meio dos recursos tecnológicos presentes no AVA e não se candidatar a esse modelo de ensino, simplesmente porque terá um acréscimo financeiro por meio de bolsas, por exemplo.

\section{CONSIDERAÇõES FINAIS}

De acordo com o que foi observado nessa experiência de ensino de espanhol na Universidade Aberta do Brasil, concluímos que a qualificação específica do professor da 
modalidade a distância é necessária para atuar neste contexto, mas não apenas no sentido de aprender a utilizar as ferramentas digitais disponíveis no AVA, mas sobretudo para o uso efetivo desses recursos tecnológicos atendendo a competências específicas do processo de ensino e aprendizagem de uma língua estrangeira, como é o caso do que foi observado referente ao ensino da escrita em espanhol.

O material produzido para essa modalidade também precisa se adequar a esse contexto de inovação tecnológica. Mesmo os impressos devem ser constantemente atualizados, principalmente no caso da $\mathrm{EaD}$, uma vez que o AVA e tudo o que circula na web muda continuamente e é por meio do próprio recurso do trabalho docente que tais mudanças didáticas podem ser geradas e percebidas na atuação do professor e na percepção dos discentes.

Os alunos, por sua vez, devem assumir o protagonismo que lhes cabe nesta modalidade de aprendizagem, não só abandonando as práticas tradicionais de estudo de uma língua estrangeira apenas focadas na estrutura que não se adequa ao perfil do aluno com foco na comunicação, mas também adaptando o que é pertinente para utilizar na aprendizagem virtual.

Ressaltamos, ainda, que o predomínio da comunicação escrita no AVA, importante habilidade para o ensino e aprendizagem na $\mathrm{EaD}$, não significa que o ensino dessa competência comunicativa esteja livre de mudanças que representem melhorias, pelo contrário, são necessários estudos que ajudem os professores a desenvolver suas tarefas nesta modalidade levando em conta os recursos específicos dos suportes virtuais da EaD para estimular a prática de uma escrita colaborativa, reflexiva, funcional e adequada ao contexto acadêmico de formação de futuros docentes de espanhol como língua estrangeira.

Por fim, conforme observado neste artigo, o ensino e a aprendizagem mediados por TDIC, embora precisem se aprimorar no contexto da EaD observado, representam um avanço em termos de socialização e ampliação das possibilidades de aprendizagem de uma língua tão importante quanto o espanhol em nível mundial, além de levar a formação universitária de forma democrática também para aqueles que moram longe dos grandes centros urbanos do país e que desejam seguir estudos superiores nesta ou em qualquer outra língua ou curso de graduação.

\section{REFERÊNCIAS}

ABARCA, M. M. La escritura como proceso: metodología para la enseñanza de la expresión escrita en español como segunda lengua. Revista de Filología y Lingüística de la Universidad de Costa Rica, v. 34, n. 1, p. 127-141, 2008. Disponível em: https://revistas.ucr.ac.cr/. Acesso em: 23 maio 2021.

ARAÚJO, J. C. Constelação de gêneros: a construção de um conceito. São Paulo: Parábola, 2021. 
ARAGÃO, R. C. Projeto forte: formação, reflexão e tecnologias no ensino de inglês na Bahia. Em: ARAÚJO, J. C.; DIEB, M. Letramentos na Web: Gêneros, Interação e Ensino. Fortaleza: UFC, 2009. p. 58-81.

BAPTISTA, L. M. R. B. O ensino da escrita em ambiente virtual de aprendizagem (AVA). In: ARAÚJO, J. C.; ARAÚJO, N. M. S. EaD em tela: docência, ensino e ferramentas digitais. Campinas: Pontes, 2013. p. 143-162.

BRASIL. Lei 11.161 de 5 de agosto de 2005. Dispõe sobre o ensino de língua espanhola. 2005. Disponível em: http://www.planalto.gov.br/ccivil_03/_ato2015-2018/2017/lei/li3415.htm. REVOGADA PELA LEI N ${ }^{\circ}$ 13.415, De 16 de fev. 2017. Acesso em: 14 fev. 2021.

BRASIL. Lei $N^{\circ} 11.161$ de 5 ago. 2005. Dispõe sobre o ensino da língua espanhola, 2005. Disponível em: http://www.planalto.gov.br/ccivil_03/_ato2004-2006/2005/lei/li1161.htm. Acesso em: 9 maio 2021.

CAIADO, R. V. R. A ortografia no gênero Weblog: entre a escrita digital e a escrita escolar. In. ARAÚJO, J. C. (Org.). Internet \& ensino: novos gêneros, outros desafios. Rio de Janeiro: Lucerna, 2007. p. 35-47.

CARVALHO, T. L. El texto escrito a través del foro en clases de ELE en la EaD: potencial didáctico versus subutilización del género. Diálogo das Letras, Pau dos Ferros, v. 9, p. 1-20, 2020.

CARVALHO, T. L. La enseñanza de la escritura en ELE en la EaD brasileña: análisis y orientaciones didácticas. Salamanca: USAL, 2018, 322 p. Tese (Doutorado em Español: investigación avanzada en Lengua y Literatura, Facultad de Filología, Departamento de Filología Hispánica da Universidad de Salamanca, Salamanca, 2018.

CARVALHO, T. L. O Gênero digital e-mail no desenvolvimento da escrita e da interação professor-aluno: uma experiência de ensino de espanhol como língua estrangeira. $250 f$. Dissertação (Mestrado). Programa de Pós-Graduação em Linguística. Universidade Federal do Ceará, Fortaleza, 2010.

CARVALHO, T. L. O professor de espanhol diante dos letramentos da web e a utilização dos gêneros digitais. In: ARAÚJO, J. C.; DIEB, M. Letramentos na Web: Gêneros, Interação e Ensino. Fortaleza: Edições UFC, 2009. p. 82-98.

CARVALHO, T. L.; COSTA JUNIOR, J. V. L. El español en la educación brasileña: desde el histórico nacional hasta las especificidades en las IES de Rio Grande do Norte. LEIA ESCOLA, v. 20, 2020, p. 305-317.

COSTA JUNIOR, J. V. L.; CARVALHO, T. L. Quando políticas de resistência se transformam em políticas linguísticas oficiais: o espanhol no Nordeste brasileiro. REVISTA X, v. 15, 2020, p. 172-193. 
CROWSTON, K.; WILLIAMS, M. Reproduced and emergent genres of communication on the World-Wide Web. Actas de la $30^{\text {a }}$ Conferencia Internacional Hawaii Anual de Ciencias del Sistema. 1997. Disponible en: http://crowston.syr.edu/papers/ webgenres.html. Acesso em: 10 jun. 2021.

DIEB, M.; AVELINO, F. C. B. "Escrevo abreviado porque é muito mais rápido": O adolescente, o internetês e o letramento digital. In: ARAÚJO, J. C., DIEB, M. (Orgs.). Letramentos na Web: Gêneros, Interação e Ensino. Fortaleza: Edições UFC, 2009. p. 264-282.

ERES FERNÁNDEZ, G.; BAPTISTA, L. M. R. B.; CALLEGARI, M. V.; REIS, M.O. B. dos. Gêneros textuais e produção escrita - teoria e prática nas aulas de espanhol como língua estrangeira. São Paulo: Ibep, 2012.

GARCÍA ARETIO, L. De la educación a distancia a la educación virtual. Barcelona: Editorial Ariel, 2007.

LEAL, V. P. L. V. O chat quando não é chato: o papel da mediação pedagógica em Chats educacionais. In. ARAÚJO, J. C. (org.). Internet \& ensino: novos gêneros, outros desafios. Rio de Janeiro: Lucerna, 2007. p. 48-63.

MOREIRA, G. L.; PONTES, V. de O. O ensino de espanhol como língua estrangeira na educação brasileira: Ceará em foco. Campinas: Mercado de Letras, 2021.

MOTTA-ROTH, D. REIS, S. C. MARSHALL, D. O gênero página pessoal e o ensino de produção textual em inglês. In: ARAÚJO, J. C. (org.). Internet \& ensino: novos gêneros, outros desafios. Rio de Janeiro: Lucerna, 2007. p. 126-143.

NUNAN, D. Research methods in language learning. Cambridge: Cambridge University Press, 1992.

PACHERREZ VELASCO, M. T. et al. Projeto Pedagógico do Curso Superior de Licenciatura em Letras Espanhol na modalidade a distância. Publicación del Instituto Federal de Educação, Ciência e Tecnologia do Rio Grande do Norte - IFRN, Natal, 2012.

SHEPHERD, M.; WATTERS, C. The evolution of cyber genres. Actas de la $31^{\text {a }}$ Conferencia Internacional Hawaii Anual de Ciencias del Sistema, 1998. Disponible en: http://web.cs.dal. ca/ shepherd/pubs/evolution.pdf. Acesso em: 20 jun. 2021.

SOUZA, R. A. de. Aprendizagem em regime Tandem: Uma alternativa no ensino de línguas estrangeiras online. In: ARAÚJO, J. C. (Org). Internet \& ensino: novos gêneros, outros desafios. Rio de Janeiro: Lucerna, 2007. p. 205-220.

Recebido para publicação em: 10 jun. 2021. Aceito para publicação em: 16 out. 2021. 